\title{
Fuentes para el estudio de la Historia de la Iglesia: Barbastro
}

\author{
Maria Jesús Llavero Porcel
}

Resumen

Se analizan los triples fondos del Archivo eclesiástico de Barbastro y se indica la tipología e importancia histórica de la documentación existente.

Palabras claves: Archivo, Tipología documental

\section{SUMMARY}

This paper analyses the three funds of the ecclesiastical Archive of Barbastro and shows the typology and the historical significance of the existing documents Keyword: Archive, Documentary Typology

\section{INTRODUCCIÓN}

Para un principiante en el "oficio" de historiador los archivos eclesiásticos, en la mayoría de las ocasiones, se manifiestan como lugares de difícil acceso con fondos ilógicos en su clasificación e ininteligibles, por ignorar las funciones del órgano administrativo que los generó. Estas dificultades han sido paliadas en parte por recientes publicaciones sobre la estructura de los archivos parroquiales y el contenido de sus fondos. Incluso existen guías no muy completas de algún archivo diocesano.

Al acceder a cualquier archivo eclesiástico hay que contar con tres condicionantes históricos que no deben olvidarse. En primer lugar, los decretos del Concilio de Trento, que poco a poco transformaron la práctica religiosa, la organización eclesiástica y las relaciones de las instituciones religiosas con su entorno social, político y económico. Esta transformación se refleja en la documentación generada durante siglos en las diferentes instituciones y organismos eclesiásticos. La potenciación de las manifestaciones externas de piedad a través de las congregaciones, cofradías y hermandades originó una rica documentación para los historia- 
dores. Una de las consecuencias más inmediatas fue la organización de los archivos parroquiales con la obligatoriedad de cumplimentar los libros de bautizos, matrimonios, entierros y cumplimiento pascual, y de llevar una contabilidad estricta de las rentas que permitían sostener a la parroquia, a «la fábrica». También se robusteció a la curia diocesana frente a la capitular al reforzar funciones, que venían de antiguo, como las visitas pastorales, el establecimiento de seminarios conciliares o visita ad limina.

El Regalismo, concretado en el Patronato real universal, es un segundo condicionante que no debe olvidarse. La presentación de los obispos de buena parte de las diócesis ayudó en gran manera a mantener ese Regalismo, y a aplicar un sentido ideológico concreto, nacional, a la organización de la Iglesia en España, y, sobre todo, a ejercer sobre el territorio la política que en cada caso le convino a la Corona.

El tercer y último condicionante proviene del propio carácter del archivo diocesano, que es fundamentalmente un archivo administrativo vivo al servicio del obispo y de su curia. El paso del tiempo, como ocurre con los libros de cumplimiento pascual, o la desaparición de una determinada institución, caso del diezmo, hace que deje de tener importancia e interés para el archivero con la consiguiente pérdida, si no física si al menos de accesibilidad, de algunas series. Desde mediados del siglo XIX hasta el último cuarto del siglo actual también la mala instalación y la dejadez ha provocado algunas veces la destrucción o el deterioro de muchos documentos, lo que dificulta aún más el acceso del neófito historiador a los fondos eclesiásticos.

El Archivo eclesiástico de Barbastro posee una característica que le diferencia con mucho de todos los demás: el triple origen de la documentación depositada en él. Como todos los archivos episcopales el archivo diocesano (ADB) se formó con la generada por la curia diocesana. A este fondo se añadió a mediados del presente siglo la de las distintas parroquias ${ }^{1}$. Finalmente, entre los fondos del archivo se incluye toda la documentación generada por el cabildo catedralicio (ACB). Este triple origen proporciona un elevado valor de la documentación conservada e indica una elevación de nivel en la formación de los archiveros diocesanos 2.

1 El traspaso de fondos documentales de las parroquias al archivo diocesano es actualmente un fenómeno frecuente tal como ocurre en el Archivo Diocesano de Oviedo y en el Santander, entre otros. Se considera obviamente como el medio más apropiado para su mejor conservación.

2 La mayor profesionalidad de los archiveros eclesiásticos se ve en la publicación de las actas del congreso que celebran anualmente con el título de Memcria Eclessiae. 
Este artículo pretende describir las series y tipologia documentales que se pueden encontrar en el archivo diocesano de Barbastro, haciendo un análisis de las estructuras que presentan los documentos y las posibilidades que brindan para el estudio de la Historia de la Iglesia. Evidentemente, este análisis no pretende ser exhaustivo y, por tanto, no está recogida la totalidad de la tipología existente, aunque sí una buena parte de ella. Los criterios para incluirlas o no, son la facilidad y el rendimiento: la facilidad de acceso físico, para encontrar las series más completas, para entender el contenido y su significado y el rendimiento que podemos extraer de su consulta, no sólo por la información primaria que presenta, sino también por la secundarias que, con poco esfuerzo, podemos descubrir en los documentos.

Felipe II aprovechó los favores hechos al Papa para solicitar la erección de una serie de nuevos obispados. En unos casos coincidieron con reivindicaciones seculares de los pueblos -Barbastro-, y en otros eran de nueva planta -Solsona y Jaca- ${ }^{3}$. Estos nuevos obispados respondían a veces a la necesidad de controlar ideológicamente las fronteras con Francia, y siempre a la intención de hacer más efectiva la implantación de las reformas religiosas e ideológicas, recortando de paso poder y territorio a algunos de los obispados más poderosos y extensos de la península.

Barbastro ya había sido erigida como sede episcopal en 1101 durante el reinado de Pedro I, tras su reconquista el año anterior. Poco tiempo después, en 1143, por un breve pontificio de Inocencio II, desaparecía la diócesis por los desgraciados sucesos que originó la pugna con la sede de Huesca por la cobranza de diezmos y primicias en diferentes lugares de la provincia. Desde entonces, y después de firmar una concordia entre el pueblo de Barbastro y el cabildo de la Iglesia que fue catedral, ambas colectivos promovieron el retorno de la cátedra episcopal, lo que originó un contencioso largo y de graves consecuencias con la diócesis de Huesca y Lleida, que se habían repartido el territorio del antiguo obispado ${ }^{4}$. Ésta fue la razón por la que en Barbastro se acogió con especial entu-

3 La ayuda en la reanudación de las sesiones del concilio de Trento, la promulgación de la mayoría de los decretos tridentinos, el apoyo en la guerra de los treinta años y la guerra contra el turco. También obedece al espiritu del Concilio que persegula un mayor control del obispo sobre las parroquias para lo que la mejor solución era dividir algunos de los obispados grandes, sobre todo en zonas de difícil acceso como en los Pirineos.

4 LÓPEz NovoA, S., Historia de la muy noble y muy leal ciudad de Barbastro y descripción geográfico-histórica de su diócesis. Barcelona, 1861, p. 140. Se ha utilizado la revisión publicada en Barbastro en 1981. 
siasmo la petición del rey, y se consideró la nueva erección de la sede obispal en 1573, concedida por Pío V, como un reconocimiento de sus derechos y privilegios históricos y una reparación de la grave injusticia que habian sufrido durante siglos 5 .

La bisoñez del obispado de Barbastro, si se compara con otros de la península que tenían tres, cuatro y hasta cinco siglos más de existencia, se refleja en la pobreza de la documentación medieval. El hecho que su instauración fuese casi inmediata a la finalización del concilio de Trento, condiciona la documentación por su tipología y por su organización. La documentación refleja las relaciones tensas y conflictivas con las vecinas de Huesca y Lérida, más grandes, antiguas y poderosas y siempre ávidas de recuperar los diezmos que les fueron separados para la dotación de la nueva diócesis.

Para los estudios demográficos el Archivo Diocesano de Barbastro ofrece tres series importantes: La primera está formada por los libros de registros parroquiales en un sentido estricto, es decir, los de bautismo, matrimonio y defunciones, obligatorios desde el Concilio de Trento. Como es sabido, poseen una gran riqueza de datos referidos a las personas, su nivel social, oficio, lugar de origen y ascendientes. Muchos de ellos poseen anotaciones circunstanciales muy útiles, como las causas de la muerte o la razón «especial» que justifica la celebración de algunos matrimonios.

No tienen todos las mismas características externas. La mayoría están encuadernados, pero pueden ser de diversos tamaños y disponer los datos en diferente orden. Hacia el siglo XVIII la distribución interna de estos datos se encuentra bastante normalizada, inscribiendo en primer lugar el sacramento que recibe y la fecha, los datos de filiación de la persona o personas en cuestión, sus ascendientes, su origen (en el caso de ser forastero), y su oficio. El que la información sea más o menos completa depende, en gran parte, del buen hacer del encargado de su anotación. En ocasiones, la ignorancia de datos concretos de filiación se suple con descripciones físicas amplias, sobre todo en el caso de las defunciones, para facilitar una posible localización de las personas en el supuesto que alguien las buscase. Las lagunas cronológicas que pueden encontrarse se deben casi con toda seguridad a desastres fortuitos, incendio, inundación, robo, etc. No se han encontrado libros de registros de "albats", es

5 Bula de elerección de la Iglesia Catedral de Babastro, 29 de julio de 1571. Archivo Capitular de Barbastro (ACB), IV, Caja con bulas y breves. 
decir, de recién nacidos que por nacer muertos o morir inmediatamente después de llegar a este mundo no han podido ser bautizados.

La segunda serie está formada por los cuadernos de cumplimiento pascual, en los que se recogen por barrios o calles los feligreses que habían cumplido la obligación eclesiástica de confesar y comulgar por Pascua Florida. Son muy útiles porque constituyen auténticos censos de población adulta que complementan perfectamente el trabajo clásico de reconstrucción de familias, proporcionando incluso datos de tipo social 6 . Aunque el deseo de controlar la actividad religiosa de la población ya se plasmó en el IV Concilio Lateranense, fue en el de Trento una vez más, cuando se comenzó su implantación que naturalmente fue progresiva. En el ADB los primeros cuadernos de cumplimiento pascual son de 1618 y la serie llega hasta 1932, aunque es sabido que el control se llevo hasta comienzo de los años cincuenta.

Por último, la tercera serie está formada por los bastardelos o minutarios, es decir, los cuadernos en que los escribanos o notarios ponían los borradores o minutas de las escrituras o instrumentos públicos que se otorgaban ante ellos. En el ADB la serie comienza en 1592 y finaliza en 1819. Su importancia demográfica radica en que desde 1794 se incluyen las profesiones de fe y las exploraciones de libertad de religiosa, lo que los convierte en una fuente importante para el estudio de la población religiosa, procedencia, origen social, edades en las que se profesa, etc.; aspectos que ayudan a entender algunos comportamientos políticos acaecidos durante la crisis del Antiguo Régimen

Es evidente que la crematística iba unida estrechamente al interés específicamente religioso de la actividad eclesiástica, por lo que se consideraba fundamental la recaudación de las diferentes rentas que debía de hacerse en el momento justo y en la cantidad que correspondía. De esta forma se mantenía un estricto control de los puntos de cobro, de la cantidad y del concepto. Era necesario, pues, conservarlos de forma ordenada para recuperar en caso de necesidad las escrituras, los cabreos 7 los resúmenes quinquenales de cuentas, los contratos de censos y arrendamientos $y$, como no, las testamentarías ${ }^{8}$. Todo ello era muy importante

6 Eugeni PEREA Simón los ha utilizado para estudiar El comportament religiós a Catalunya al segle XIX a la diocesi de Tarragona. Reus, 1993, p. 32 y 33.

7 Libros que servian para anotar los privilegios y pertenencias de una iglesia.

8 También existían funciones, como la notarial y la de recaudadores de impuestos para la Corona - excusado, el noveno, etc.- entre otras que, si bien no eran exclusivas del ámbito eclesiástico, reportaban una buena parte de las aportaciones al pecunio obispal, catedralicio o parroquial. 
para una diócesis como Barbastro, que como ha estudiado Maximiliano Barrio, tenía una de las rentas más bajas de España ${ }^{9}$. Asi pues, cualquier cosa que ayudara a aumentar los ingresos, debía de ser cuidado, controlado, potenciado y defendido.

La mayor parte de la información sobre la contabilidad originada por los diezmos y primicias, que constituían el grueso de los ingresos de las instituciones eclesiásticas, se encuentra recogida en libros de tamaño folio formados al encuadernar conjuntos de cuadernillos o bien de cuadernillos y hojas sueltos. En el peor de los casos, hay que reconstruirlos a través de los testimonios que se reparten en la documentación de diferentes pleitos, con el consiguiente cuidado por la subjetividad de los testimonios que aportan 10.

El encargado de llevar los libros de diezmos y primicias en las parroquias era generalmente el propio párroco, cuya falta de formación suficiente para esa tarea se refleja en las anotaciones y en los resultados. En los cabildos catedralicios y los colegiales era un cargo rotatorio, mientras que en la curia diocesana se detectaba una mayor continuidad de las personas, aunque era relativa si se tenía en cuenta la duración de algunos obispos en sus cargos. La diversidad de los contables originó una gran falta de uniformidad tanto en el formato de los libros como en la introducción de datos.

En su interior se organizaban, en primer lugar, por quinquenios generalmente, y después geográficamente e incluso por instituciones, si eran lo suficientemente importantes. En cada uno de estos apartados la información se clasificaba por productos: los agropecuarios, en primer lugar, seguidos por las rentas de servicios, y finalmente por los ingresos que generaban diferentes inmuebles o instituciones. El orden no siempre se mantuvo pero solía ser el más habitual, ya que estaba en correlación con la importancia de los ingresos. Estos conceptos normalmente vienen recogidos en columnas en las que también se presenta la recaudación inmediatamente anterior y la presente. Es frecuente encontrar comentarios a las dificultades de recaudación, de venta o almacenamiento, a incidentes violentos 0 a los beneficios o pérdidas obtenidos. Existen resúmenes periódicos que se presentaban, bien en cada relevo de la persona encargada, a petición de la curia correspondiente o con una periodicidad establecida de antemano. Estos rendimientos de cuentas o están recogidos

9 Callahan, W. J.: Iglesia, poder y sociedad en España, 1750-1874, p. 16.

10 Libro sobre pleito con la ciudad en frutos decimales y primiciales. 1629. A.D.B, II. 
de forma más o menos resumida en las actas de reuniones, -en el caso de los cabildos-, o se hacen referencia a los resúmenes presentados y a su localización, que desgraciadamente no suele ser la actual.

En la mayor parte de los casos las dos contabilidades, tanto la diocesana como la capitular, se recogen indistintamente en un solo libro, aunque pueden estar en varios ${ }^{11}$. En ambos casos responde más a una organización personal del encargado de llevarlos que a una justificación de técnicas contables que permitiesen un mayor o mejor control. La organización en uno o dos libros puede deberse también a cuestiones externas, como la necesidad de aplicar las primicias a la fábrica de la iglesia 0 a situaciones de mayor control económico, recibiendo entonces el nombre de libros clavarios, de bolsería o de contabilidad 12 .

Documentación afín a los diezmos y primicias son los libros de arrendamientos que recogen los contratos de arriendo y su recaudación ${ }^{13}$. Esta tipología documental presenta una larga cronología aunque a veces con grandes lagunas documentales, sobre todo en épocas de crisis y revoluciones. La mayor parte de los libros se centran cronológicamente entre el primer cuarto del XVIII y el segundo tercio del pasado. Hay también libros desde el siglo XV, anteriores a la reinstauración de la diócesis, como los del fondo de los monasterios de Montearagón y de San Victorián, ya que sus rentas se asignaron para el sostenimiento del nuevo obispado. No es difícil imaginar que la consulta de esta serie resulta muy provechosa para estudiar las fluctuaciones agrarias, la implantación de nuevos cultivos, la evolución de los precios o la comercialización de los productos.

Los censales, libros que recogen los censos o contratos por los que se sujeta un bien inmueble al pago de una pensión anual, como interés de un capital recibido en dinero, con el reconocimiento de un dominio que no se transmite con el inmueble, pocas veces pueden encontrarse relacionados de forma sistemática salvo cuando forman parte de los expedientes judiciales como pruebas documentales. En este caso, como en el de los diezmos y primicias, hay que verlos con atención y cuidado por la prolife-

11 Libro de Diezmos y primicias de la diocesis. Predios y rentas de las parroquias. Valores por quinquenios, 1821. ACB, II.

12 Como ejemplo de la amplia variedad que en el archivo de Barbastro adoptan los formatos y modos de instalación de los diezmos y primicias valgan estas dos referencias: Caja con Montearagón: diezmos y primicias de su abadiado; III Libro de contabilidad, 1569. ACB, II y ADB, Rentas decimales, 1684-1936, legajos 856-859.

13 ACB, II, Libro de Arrendamientos del Cabildo 1609-1635 
ración de alardes que poseen. Los censales suelen estar organizados en legajos o carpetas donde se encuentra no sólo las escrituras sino también los contratos, recibos, normativa, concordias, etc. La documentación proporciona tanto información jurídica como comercial, financiera y social. Además de la clasificación temática, suelen tener una ordenación cronológica y geográfica, e incluso onomástica cuando se refieren a fincas con nombre propio. La variedad de la tipología documental es tan amplia como los fondos que se pueden consultar ya que pueden ser libros ${ }^{14}$, cajas o legajos que incluyen las escrituras de propiedad o venta y el resto de la documentación relativa a la gestión de los censos 15 . Como en el caso de los diezmos, la cronología de los censales recogidos en Barbastro es amplia y difícil de centrar por su propia característica de «cajón de sastre». De una primera aproximación a los censales se puede deducir que durante el primer tercio del siglo XIX existió una gran resistencia a satisfacerlos lo que provocó conflictos y reacciones desmesuradas, y sobre todo la necesidad de tener a mano la documentación para probar ante los tribunales su existencia. La investigación de los censales permite llevar a cabo estudios sobre el crédito, el endeudamiento rural o los sistemas de controi del mercado financiero, entre otros temas.

La reducción del diezmo por las Cortes del Trienio en 1821 trajo consigo la aparición de un nuevo órgano eclesiástico porque «para respetar la libertad e independencia del clero en la gestión de sus nuevas rentas se habría de constituir en la capital de cada diócesis, para su distribución, una Junta del clero o Junta Diocesana integrada por el Prelado diocesano, por sí o mediante representación, dos diputados por el cabildo y seis en representación de los curas párrocos» 16. En Barbastro, la Junta Diocesana del medio diezmo generó una copiosa documentación durante los dos períodos de su existencia: 1821-1823 y 1832-1846. Parte de ella tiene un carácter eminentemente económico puesto que se refiere a las rentas que se cobraban en cada una de las instituciones religiosas de la diócesis. Son escasas las referencias a la participación de los laicos en estas rentas pero abundantísimos los alardes de gastos y las justificaciones para cobrar la totalidad de ellas por ser, naturalmente, de derecho divino.

14 ACB, IV, libro de censales de la Cofradía de la Almas 1764-1806.

15 ACB, IV, Caja con compras y ventas de fincas. Idem de censales, 1536-1759.

16 El estudio más completo sobre el medio diezmo lo constituye el artículo de MonTOLIU, Ricardo, «El medio ciezmo. Un episodio en la ref́orma eclesiástica del trienio liberal (1820-23)» en Hispania Nova. Revista de Historia contemporánea, http://hispanianova.rediris.es. La legislación se encuentra también como impresos en el archivo de Bartastro. 
Del período de pleno funcionamiento de la Junta se conservan los instrumentos de cobro y control del medio diezmo y los informes periódicos que se enviaron a Madrid sobre la aplicación de esta renta. También se encuentran las actas de la Junta en las que se recogen las propuestas de los componentes, las dificultades de cobro y de gestión y los conflictos que generaron, es decir, el día a día de esta institución ${ }^{17}$. Tanto las actas como la documentación económica se ciñen, tipológicamente a la estructura normal de una y otra. El estudio de esta institución constituye el tema de mi tesis doctoral, actualmente en curso, que realizo bajo la dirección del Dr. Montolío.

Los eclesiásticos por su nivel cultural y el carácter de su propio cargo fueron en un primer momento los depositarios de la fe pública, por lo que ejercieron de notarios y secretarios de la nobleza, de instituciones públicas o privadas. Cuando se generalizó la contratación de notarios seglares, los eclesiásticos pretendieron actuar de notarios libres, lo que originó muchos conflictos que finalizaron con la exclusión de los clérigos de la fe pública. Como las notarias se poseían por privilegio, las diferentes instituciones eclesiásticas que ostentaban este privilegio lo mantuvieron, bien arrendándolas o bien nombrando sustitutos seglares a los que cobraban una cantidad fija establecida en contrato. De esta forma las funciones notariales siguieron devengando beneficios. Estas entradas se recogen en cuadernillos anuales de contabilidad, más o menos explícitos en sus datos, que reciben el nombre de "testamentarias" en los índices e inventarios. En el caso de Barbastro esta contabilidad se encuentra en el fondo del archivo diocesano con una cronologia que va de 1548 a 1788 18. Evidentemente dentro de la documentación referida a la notaria una parte importante son los bastardelos.

Las diferentes instituciones diocesanas percibian numerosas rentas por diversos servicios de los que eran titulares por propiedad o por donación de las rentas. Estos servicios podían ser hornos, molinos de aceite 0 de harina, batanes, fraguas y forjas, graneros, tierras, ganado, inmuebles, etc. En su mayor parte su gestión era objeto de arrendamiento a una tercera persona por un tanto alzado que se cobraba periódicamente 0 al perfeccionarse el contrato. La contabilidad, que se recoge en cuadernillos unidos en legajos, puede incluir la documentación de la subasta y el contrato de arrendamiento del cobro de las rentas. La tipología de estos con-

17 Junta diocesana 1832-1846. ADB, legajos, 610,611 y 812. Libro de Actas de la Junta diocesana 1821-1823 y Caja con subsidios, Medio-diezmos y primicias 1821-1823. ACB, I.

18 ADB, legajos $432,433,792$ y 793. 
tratos de arrendamiento es variada en las cláusulas, la duración del contrato y los plazos para el cobro según la costumbre de cada zona y dependiendo del objeto del arrendamiento por lo que los datos contables vienen establecidos por las cláusulas de los contratos. En muchos casos estas rentas hay que descubrirlas en la generalidad de entradas económicas, libros de bolsería, de contabilidad de la mensa o comunerias, etc.

Los datos que proporcionan ayudan, en muchos casos, a seguir la evolución tecnológica, ya que también recogen las mejoras que se fueron introduciendo, y por supuesto facilitan el concretar con cifras las épocas de crisis, porque los servicios mencionados detectan rápidamente las fluctuaciones. Hay una visible evolución en el modus operandi del cobro que va desde el control directo de la primera documentación al arrendamiento para el cobro de las rentas o de la gestión total. Por su propio carácter tienen una cronología amplia que llega al siglo XIX.

Dentro del campo cultural hay que destacar los fondos relativos a las visitas pastorales. Iniciadas por la costumbre desde antiguo, tanto las constituciones sinodales como el propio concilio de Trento sancionaron el deber episcopal de visitar las parroquias de las diócesis al menos una vez al año para inspeccionar al clero, supervisar la práctica religiosa y comprobar el nivel de la población. Por esta visita se recibía una paga aneja, pro iure visitationis, que en algunas diócesis, con la normalización de la práctica de las visitas y la precariedad de la economía eclesiástica del siglo XIX, se decidió que sólo se recibiese una vez al año aunque, por necesidad, se visitase una parroquia más veces en ese plazo ${ }^{19}$.

Estas visitas quedaban recogidas en libros que reciben diferentes nombres: «visitas pastorales», «libros de la santa visita», o simplemente "visita». En ellos se recogian todas las circunstancias que se considerasen dignas de resaltar y todo lo que se debia mejorar, rectificar o aplicar en el culto, en la administración de la parroquia o en la vida social y cultural de la población. Por esa razón han sido y son utilizados cada vez con mayor frecuencia, como fuentes para conocer la vida cotidiana, la formación del clero rural o el control social ejercido por la Iglesia. Los libros de visita forman en los archivos diocesanos grandes series escritas desde el sigio XIV, pero en el caso de Barbastro se encuentran recogidos y ordenados cronológicamente de forma continua desde $1637^{20}$. También hay

19 Alfred Gusti FarRenY muestra el caso de Tarragona en 1866. «Algunes fonts per a l'estudi de la Història de l'Església de Lleida (segles XVI-XVIII)" en Actes del I CONGRÉS D'HISTORIA DE L'ESGLESIA CATALANA DES DELS ORIGENS FINS ARA. 1993, Vol 1, pp.29-43.

20 ADB, leg. 831 y 831 bis. 
documentación del siglo XV junto con las visitas ad limina o entre los fondos parroquiales 21 .

Como muestra de sumisión al Papado los obispos, en el momento de su consagración episcopal, se comprometían a visitar personalmente cada cuatro años las tumbas de los apóstoles Pedro y Pablo en Roma y a dar cuenta al Papa de la situación material y espiritual de sus respectivas diócesis. Bajo el nombre de visitas ad limina están los expedientes que recogen la documentación generada siendo el documento más importante el informe que los prelados presentaban en la Santa Sede sobre la actividad apostólica llevada a cabo durante el cuatrienio anterior y el desarrollo de la vida religiosa en su territorio. La consulta de esta documentación ha servido a Pilar Pueyo Colomina para dar una visión, no muy profunda, de la diócesis de Barbastro en el siglo XVIII 22.

En la sección cuarta del libro de inventario del archivo capitular se encuentra la documentación, de 1417 a 1833, referente a las cofradias.

21 ADB, leg. 888 y 889.

22 Existe una instrucción de 1725 en la que se daba una guía de los temas que debian tratar estos informes, aunque podian contener otros que se consideraran importantes. En ella se proponía un esquema de informe con diferentes apartados, subdivididos a su vez en temas, intentando abarcar toda la problemática episcopal, desde la creación del obispado a la marcha de su administración, la práctica religiosa y el control del clero secular y regular, entre otros aspectos. El expe. diente refleja también los preparativos previos en la propia diócesís. En él suele aparecer la consulta por parte del obispo de turno del informe justamente anterior, en algunos casos incluso los dos o tres anteriores, de los que puede aparecer un resumen más o menos escueto o solamente la referencia, a lo que se adjunta el cómputo del cuatrienio y la decisión, por escrito y justificada, de hacer personalmente la visita o delegar en otra persona. Por la documentación existente en Barbastro y por la bibliografía al respecto, parece ser que lo frecuente era, hasta el siglo XIX, que delegara en miembros de su cabildo, si estos aceptaban, si no, lo proponía al bajo clero secular o regular de la diócesis, y en último lugar a aquellos que, siendo del obispado, por diferentes motivos se encontraban en Roma o residían en ella. Cada una de las renuncias debia quedar plenamente justificada, tras lo cual se recogian en un documento que se adjuntaba al expediente. Una vez nombrado el representante o procurador, se trasladaba a Roma llevando: las excusas, su nombramiento, una carta del obispo dirigida al Papa y otra para la Santa Congregación del Concilio que se incluían en el mismo informe sobre el estado material y espiritual de la diócesis. Ya en Roma este procurador debía visitar las tumbas de los apóstoles de lo que se le daba un certificado que junto con el resto de la documentación lo depositaba en la secretaría de la Sagrada Congregación del Concilio y alli se le expedía un nuevo certificado del cumplimiento del cuatrienio (atestatio visitationis), que retornaba a la diócesis y se adjuntaba al referido expediente. También se unía a él la respuesta que desde la referida secretaria era remitida, como contestación a la carta del prelado, donde se hacían observaciones sobre aquellos asuntos que lo requerían. Cfr. PUEYo COLOMINA, Pilar "La diócesis de Barbastro en el siglo XVIII a través de las visitas ad limina" en Somontano, Revista del Centro de Estudios del Somontano de Barbastro, 1994, 4, páginas 173-190. 
Aunque la documentación de cada una de ellas forma una unidad, existe documentación mezclada de varias de las cofradías debido, quizás, a sucesos externos. Por ello entre la documentación referida a los planes beneficiales y a las desamortizaciones, también se encuentran papeles que pertenecieron a estas instituciones y seguramente fue necesaria su separación del fondo original para testimoniar la propiedad plena, en un intento desesperado de conservar las propiedades que habían hecho posible la actividad y su evolución. No es posible determinar si las cofradías que se recogen en el archivo capitular eran todas las existentes, pero si se puede afirmar que eran muchas, una veintena, para una diócesis pobre en bienes y escasa de población. La tipología documental es variada y no hay homogeneidad entre los diferentes fondos. Se recogen libros de actas, de cuentas, libros de hermanos, de fundaciones, inventarios, contratos de compraventa, censales, arrendamientos de rentas y tierras, estatutos, obligaciones, pleitos, etc. También los legados y donaciones forman parte de todo este conjunto que posee una ordenación física más o menos cronológica.

Como corresponde a la época de la documentación, todas tienen un carácter marcadamente religioso, siendo incluso sus componentes, en algunos casos, únicamente clérigos. La documentación más antigua, 1417, pertenece a la de San Miguel de Puertas de Huesca 23. Las que poseen más volumen y con series más completas son: la de las Almas, la de la Asunción, la de los Clérigos, y la de San Pedro. Unas son afectas a una ermita o santuario (Figueruela, Virgen del Pueyo), o a la devoción de un santo de cierta ascendencia en la población, o patrón de algún oficio al que pertenecían los cofrades (san Ramón, san Antonio de Padua, san Vicente). La variedad de la documentación, el tamaño de las instituciones y el período amplio que recogen hacen que sea muy interesante su estudio. También su carácter independiente de la Iglesia, a la que pertenece, y a la que por diferentes intereses se pudo llegar a enfrentar de forma más o menos abierta, potencian esa calidad de peculiar e interesante.

El obispo ejercía la potestad judicial a través del Tribunal eclesiástico presidido por el «discreto»provisor. En Barbastro la documentación referente a este órgano judicial está clasificada bajo los epígrafes de «Procesal Civil», "Matrimonial», "Criminal", "Procesal administrativo", "Firmas de derecho", "Competencias" y "Recursos de derecho». Cada

23 Probablemente su origen se debe situar cuando Barbastro pertenecía al obispado de Huesca. 
uno de estos apartados recoge una documentación más o menos homogénea: libros de registro, de procesados y causas en las que se puede seguir la tramitación del expediente hasta su archivo definitivo o provisional, pasando por la resolución acordada, su ejecución, los diferentes recursos que se interponen y las resoluciones y ejecuciones de esos recursos. En el caso de las "Firmas de derecho" encontramos expedientes de reconocimiento de firmas en los actos de otorgar poderes para pleitos, negocios o gestión de patrimonio. El epígrafe "Competencias" recoge los expedientes en los que se analizaban la posibilidad de tener, o no, competencia sobre un asunto bien por el propio órgano o por uno superior, de oficio o a instancia de parte.

El volumen generado por esta función judicial se recoge en numerosos legajos que cronológicamente van de 1517 a 1875, con algunas lagunas debidas sobre todo a que en el momento que una causa era reclamada por un órgano superior se trasladaba toda la documentación sin hacerse ninguna anotación, por lo que no hay concordancia entre el libro de registro respectivo y las existencias en el archivo. Como cualquier documentación judicial, la del Tribunal eclesiástico es rica en datos concretos de relaciones comerciales, de vecindad o de parentesco to que permite un mayor conocimiento de la historia cotidiana.

Para el conocimiento de la organización de la diócesis, de las formas de acceso y promoción a los puestos de trabajo, de la extracción social y nivel cultural de las personas que entraban a formar parte del estamento clerical, el archivo de Barbastro posee cinco series muy útiles que no han sido todavia estudiadas con la profundidad que se merecen.

La primera de ellas se titula Provisiones y recoge a lo largo de una veintena de legajos los expedientes formados ante la necesidad de cubrir una plaza eclesiástica por presentación real, eclesiástica, laica o mixta. El período que comprende comienza en 1576 y finaliza en 1845. La provisión se iniciaba con la notificación al obispado o al patrón, laico o eclesiástico, de la vacante producida y de la necesidad de cubrirla en el plazo más breve posible. Finalizaba con la toma de posesión de la persona elegida. Durante la tramitación los pasos varían dependiendo del puesto a cubrir, de la categoria, rentas adjuntas, requisitos que se solicitan. También, aunque no siempre, hay una pequeña encuesta que se hacia a los pretendientes del cargo o el resumen de lo que parece debía ser una entrevista personal. La elección final y el nombramiento lo llevaba a cabo, normalmente, el obispo o el patrón respectivo de entre una terna que les era presentada. 
La segunda serie está formada con la documentación generada por las oposiciones, Concursos, que se realizaban para cubrir la plantilla de párrocos. En Barbastro esta documentación, cuyo volumen es considerable, abarca de 1805 a 1920. Si en las provisiones prevalecía la intención del patrón aunque se buscara la buena formación del candidato y su incuestionable categoría moral, en el caso de los concursos eran los méritos los que decidían teóricamente la ocupación del cargo. El concursar no siempre suponía una mejora del nivel económico, sino que se trataba simplemente de un traslado geográfico. También como en el caso de las provisiones, los concursos generaban toda una serie de documentación referida a los listados de plazas y de las características exigidas en cada una junto con una variada correspondencia entre los diferentes obispados, el Consejo o incluso entre capítulos, en la que se solicitaba información sobre los concursantes o sobre los mismos concursos. Los concursos se complementaban con las resultas, las plazas que dejaban libres aquellos que habían ganado el concurso y a las que optaban los que quedaban.

La documentación que se creaba cuando dos clérigos deseaban cambiar sus beneficios de forma recíproca forma la tercera serie titulada Permutas. A pesar de que su cronología también es amplia, 1588-1775, las permutas sólo ocupan tres legajos (del número 423 al 425). La mayor parte de esta documentación ni siquiera forma expediente, ya que la negociación y decisión se adivina previa a la notificación del deseo de permutar un beneficio por otro. En los casos en que si hay expediente se puede iniciar por la noticia que daba un clérigo de su disposición a permutar su beneficio (en la mayor parte de los casos de posesión reciente o incluso sin haberla tomado aún), por otro del mismo nivel y categoría, a lo que, en algún caso, se adjuntaba una explicación de la carrera religiosa del solicitante y alguna carta avalando su categoría personal y religiosa.

Las actas en las que se recoge la filiación del que toma posesión de una plaza, la descripción del órgano ante el que la toma y las características de la plaza que ocupará se encuentra desde 1637 a 1868 en dos legajos del archivo diocesano con el título Tomas de posesión. En el archivo capitular las actas de Tomas de posesión se hallan en los libros de actas del capítulo, a veces formando parte de las actas de reuniones de este órgano durante la que se ha hecho el acto.

Finalmente hay que tener en cuenta la serie dedicada al Seminario. Desde el concilio de Trento la fundación de un Seminario para la formación del clero, especialmente para los que debían de ejercer la cura de almas, 
fue un objetivo principal para todos los obispos. En Barbastro, la creación del Seminario Conciliar tuvo un desarrollo y desenlace peculiar. Gracias a la intervención de Francisco Ferrer y Paul se fundó una Casa Seminario en Castejón del Puente, que vino a suplir las clases de Gramática y Doctrina que se daban en la curia diocesana. La Casa Seminario se trasladó en 1759 a Barbastro con el apoyo efectivo de los sucesivos obispos que la consideraban como Seminario Episcopal conscientes de que no cumplía los requisitos necesarios para ser un Seminario Conciliar. La Casa y los bienes que la sostenían fueron afectados por la desamortización con lo que tuvo que cerrar sus puertas y no será hasta 1854 que se vuelve abrir, después de haber conseguido la devolución de parte del edificio primitivo, esta vez ya como Seminario Conciliar ${ }^{24}$. Todo lo anterior justifica que parte de la información referida al Seminario se encuentre dispersa entre los informes a la curia romana que se incluyen en las visitas ad limina, en la correspondencia con diferentes organismos civiles -Ayuntamiento, Consejo de Castilla, Roma- y en la documentación referida a los Padres Paules que eran los que se encargaban de la gestión del Seminario episcopal.

El primero de los dos legajos de documentación que existen con el epigrafe "Seminario» está formado por correspondencia e informes donde se exponian tanto la situación precaria del obispado, que impedía la dotación del Seminario, como la búsqueda de soluciones para suplir esa carencia. La documentación está fechada desde el primer tercio del siglo XVIII hasta los primeros años del XIX. En el segundo legajo ya hay documentación contemporánea generada a raíz de diferentes problemas de mantenimiento de las instalaciones -oficios, informes, presupuestos- y de problemas surgidos con el régimen de la II República -correspondencia oficial, órdenes-. Lógicamente la documentación propia del seminario se encuentra actualmente en su archivo.

La gran cantidad de beneficios insuficientemente dotados, incongruos, que obligaban a malvivir a aquellos que los detentaban hizo que la monarquía borbóbonica con la ayuda de los obispos, más o menos concienciados de las nuevas ideas ilustradas, intentara desde la segunda mitad del siglo XVIII la racionalización y dignificación de los cargos eclesiásticos. Este proceso que la historiografía define con el nombre de reforma beneficial se planteó desde la Corona y, por tanto, no es una iniciativa que surge de la misma Iglesia, sino que ésta se limita a aplicar más o menos

24 La historia del proceso de creación del Seminario se relata en dos obrillas manuscritas: las Relationes rerum Ecclesiae et Diocesis Barbastrensi (1590-1837) y los Apuntes sobre la fundación de este Seminario. Ambas obras carecen de fecha y lugar de edición. 
diligentemente las órdenes que le son dadas por el gobierno desde el Consejo de Castilla. Esta circunstancia hay que tenerla en cuenta al analizar la documentación existente porque dependiendo del íntimo convencimiento que el obispo de la diócesis tuviera de la necesidad de la reforma, el Plan beneficial para el arreglo de su diócesis podía ser un reflejo de la realidad, una sombra de él o simplemente no existir.

El obispo de Barbastro, don Diego Rivera Fernández de la Vequera recibió la circular del Consejo de Castilla del 5 de julio de 1758 para que informase de los beneficios simples e incongruos que hubiese en su diócesis y que fuesen de provisión real en los meses reservados, especificando cuáles se podían reducir, en qué número y renta y con qué cargas y obligaciones; cuáles podían unirse a los curatos de poca dotación o suprimirse y unir sus rentas a fábricas de iglesias, hospitales u otros lugares píos que lo necesitasen 25 .

Inmediatamente, en 1759, el obispo envió a los capítulos de la catedral y de las colegiatas y a los diferentes arciprestazgos una circular para clarificar el contenido de la orden del Consejo y justificar sus motivos. Según el obispo «se han de hacer todas las supresiones y reducciones para que no quede ningún beneficio que no sea residencial ni útil a la Iglesia y que sea suficiente para el decente sustento de su poseedor" de forma que «aparezca el estado que tendrán en lo sucesivo las iglesias» 26. La información recibida por el obispo adolece de errores, ocultaciones y falsedades que se detectan al comparar las diversas versiones que se elaboran hasta conseguir la aplicación total y definitiva, o cuando se cruzan datos de un plan sectorial y otro diferente pero de la misma iglesia. A pesar de ello son interesantes por la relación de puestos de trabajo que muestran: divididos según categorías y niveles, recogen todo el personal beneficiado que sirve la parroquia con descripción de las funciones y obligaciones y de las rentas que los sustentan, incluyendo también a los cargos que no poseían beneficios.

El obispo valoraba las necesidades de clérigos y las rentas que tenía la parroquia tanto para atender al sustento de sus párrocos y vicarios, como a la fábrica de la iglesia y a las necesidades del culto. Según esta valoración, proponía las reducciones o supresiones de beneficios o inclu-

25 El 12 de junio de 1769 se amplió la petición de informe a todos los beneficios, fueran de presentación libre, o de cualquier tipo de patronato de los existentes y el 26 de junio de 1776 a las órdenes militares.

26 ADB, legajo 794 «Asuntos beneficiales». 
so la aplicación de otras rentas ajenas a la parroquia para atender a su sustento o se pedía el arbitrio de medios para socorrer la situación en la que se encontraban. De todo ello se pasaba el plan de arreglo beneficial al Consejo de Castilla para que lo aprobara y asi poder proceder a su aplicación. En este organismo se oía a las partes nuevamente, ya que podían presentar alegaciones en contra (incluso cuando supuestamente se había consensuado el plan). Después de estudiadas todas las aportaciones, el Consejo, dictaba resolución dando el visto bueno al referido plan o daba instrucciones para rectificar algún punto.

De acuerdo con estas directrices se fueron elaborando desde 1760 los diferentes planes beneficiales de la diócesis comenzando con el del cabildo que fue aprobado, después de introducidas modificaciones, en 1771 ya en el mandato del obispo don Juan Manuel Cornel Larriba. Este plan finalmente no se aplicó al descubrir en él falsedades el nuevo prelado, Abad Lasierra, que propuso un nuevo plan en 1796, con la oposición abierta del Cabildo, y otro en 1805 que, si bien fue acordado conjuntamente, el clero catedralicio intentó que no se aplicara, lo que demuestra las tensiones existente entre el obispo y los canónigos y la oposición de éstos a modificar su status privilegiado. En el resto de la diócesis existen los mismos problemas, resistencia de los propios beneficiados o falta de interés en aplicar el plan una vez aprobado, aunque hay que destacar la oposición que manifiestan los patronos de los beneficios. La aplicación del plan beneficial originó una serie de expedientes de arreglos parroquiales, cuya cronología es posterior puesto que comienza en 1796 con el primer decreto de aplicación del obispo Abad Lasierra 27. En Barbastro existen los expedientes de arreglos parroquiales que se realizan a mediados del siglo XIX como consecuencia de la firma del Concordato con la Santa Sede por los moderados 28.

La documentación recogida bajo el título de «Desamortización» afecta explícitamente a la realizada durante el Trienio liberal y a las dos clásicas de Mendizábal y Madoz. El criterio de ordenación viene determinado por la publicación de los decretos y la relación de bienes afectados. Como no existe ningún órgano eclesiástico dedicado a la desamortización el fondo puede considerarse como un auténtico "cajón de sastre" donde se puede hallar: relaciones de bienes afectados, escrituras de compra o de venta, informes de alegaciones para los expedientes administrativos $y$, naturalmente, toda la tramitación de cada expedientes, -notificaciones de

27 ADB, legajo 894. «Erección de parroquias y vicarías perpetuas».

$28 \mathrm{ADB}$, legajo 895 "Arreglos parroquiales y erección de vicarías 1854-1866.» 
apertura, de resoluciones, del señalamiento de la subasta, de su resultado- junto con los apremios, avisos, circulares y oficios que se recibían. También está la documentación de los bienes que, ya en la segunda mitad del siglo XIX, fueron retrotraídos a la Iglesia, la mayor parte de ellos al no haberse realizado la subasta por diferentes razones, y aquellos en los que se llegó a un acuerdo para su devolución como ocurrió con el edificio del Seminario.

Germán Rueda ha señalado certeramente la tendencia de los historiadores a delimitarse en la llamada «buena documentación abundante, bien conservada, clara, con series largas". Esta tendencia ha llevado a no tener en cuenta la riqueza de la documentación propiamente eclesiástica que completa con mucho a la civil.

Finalmente, no se deben olvidar las colecciones de correspondencia, oficiales o personales, de los diferentes miembros de las curias y que dan una visión más del día a día, e incluso muestran tendencias personales ante diferentes circunstancias. La correspondencia oficial se agrupa por la institución de la que proviene o a la que se contesta y dentro de ésta se divide cronológicamente. La privada se agrupa con la documentación de la persona que la ha generado y también con una ordenación cronológica. 